\title{
Was Art as Experience Socially Effective?
}

Dewey, the Federal Art Project and Abstract Expressionism

\section{Roberta Dreon}

\section{(2) OpenEdition \\ 1 Journals}

Electronic version

URL: http://journals.openedition.org/ejpap/606

DOI: 10.4000/ejpap.606

ISSN: 2036-4091

Publisher

Associazione Pragma

\section{Electronic reference}

Roberta Dreon, « Was Art as Experience Socially Effective? », European Journal of Pragmatism and American Philosophy [Online], V-1 | 2013, Online since 16 July 2013, connection on 19 April 2019. URL http://journals.openedition.org/ejpap/606 ; DOI : 10.4000/ejpap.606

This text was automatically generated on 19 April 2019.

\section{(c) $($ ) $\odot$ (8)}

Author retains copyright and grants the European Journal of Pragmatism and American Philosophy right of first publication with the work simultaneously licensed under a Creative Commons AttributionNonCommercial-NoDerivatives 4.0 International License. 


\title{
Was Art as Experience Socially Effective?
}

\author{
Dewey, the Federal Art Project and Abstract Expressionism
}

\section{Roberta Dreon}

1 From a comprehensive reading of his work it is by now clear that Dewey's aesthetics using the term in its broad, colloquial sense - stemmed from very strong political and social demands, and sought to be translated into concrete actions. ${ }^{1}$ In publishing Art as Experience in 1934, at the age of 75, the American philosopher did not intend to fill a specific gap in his thought by developing a philosophy of art. His point was certainly not to describe a supposedly independent field of art by outlining the alleged conditions of existence and interpretative categories of art itself. In contrast, Dewey claimed it was necessary to inquire into the reasons for the current isolation of aesthetic experience compared to other vital practices, to ask what functions the arts could perform compared to other forms of experience and whether these functions were performed adequately, and finally to help change them if necessary "by restoring the continuity of aesthetic experience with the normal processes of living."

2 One of the fundamental convictions characterizing both Dewey's thinking and his conduct was that active participation in artistic practices, in terms of both production and reception, is a significant component of social and political action. The abolition of barriers between elitist arts and other cultural forms, in his view, would encourage greater accessibility to artistic practices. On the other hand, promoting cross-distinctions between good and bad artistic experiences would contribute to the education of citizens, making them more aware and more able to contribute to common life. According to Dewey, we need a more subtle form of discrimination: some experiences are good because they are fruitful, innovative and able to enhance life experiences, as well as to call into question consolidated habits of behavior and thought, while other experiences are bad because they are ineffective: because they restrict themselves to glibly confirming existing situations, without any significant reworking. ${ }^{3}$ Above all, however, Dewey's basic thesis was that an aesthetically significant and rich experience can be a basic factor in 
building a participatory democracy, provided it is not confined to museums or the leisure time of a privileged few, expunged from the factories, and considered extraneous to politics and ethics, as well as scientific inquiry. Clearly this conception of democracy was not defined solely in terms of formal procedures, but was considered capable of responding to individuals' needs for satisfaction and self-fulfilment, while at the same time not imposing on each of them a predetermined hierarchy of values and goods, not least thanks to the critical role that culture could perform with respect to consolidated habits and pre-reflective morality. ${ }^{4}$

3 Although this concept was only fully developed in Art as Experience, many elements had been anticipated in earlier decades: not only with The Public and Its Problems in 1927 and Experience and Nature in 1925, but also in 1922 with Human Nature and Conduct, and much earlier with Democracy and Education (1916), and even the first version of Ethics in 1908. This assumption also shaped Dewey's pedagogical practices and in particular his Laboratory School, where the arts were not simply introduced to enrich curricula by guaranteeing access to the most refined cultural traditions. Rather, they were taught and practized as activities capable of meeting young people's vital needs, of enhancing their skills and channeling their energies, in such a way as to help them acquire a range of "intelligent habits" - that is to say, flexible and fruitful ones, capable of encouraging forms of critical reappraisal within shared practices.

4 This same belief was also at the basis of Dewey's involvement in a number of social initiatives, such as Jane Addams' Hull House, where artistic and craft activities, in the wake of the Arts and Crafts Movement, were intended as at least partial contributions to the problem of urban economic and cultural poverty in Chicago at the turn of the nineteenth century.

5 On the other hand, it is plausible that the worsening of the economic and social crisis in the USA in the late twenties helped to reinforce Dewey's decision to deal extensively with the aesthetic implications of his thought, starting from his criticism of the "museum conception of art," rooted in the "compartmentalisation" of life produced by industrial capitalism.

6 Victoria Grieve's painstaking reconstruction has finally shed light on the direct influence of Dewey's thought on the development of the Federal Art Project - an influence that was broadly exercised through Dewey's ethical and political reflections - gaining ground thanks to the prevailing crisis - but which was also directly exerted on Holger Cahill, the head of the federal programme in support of artistic practices between 1934 and 1938. ${ }^{5}$

7 It is evident that the cultural policy of the Federal Art Project cannot be regarded as a practical translation of Dewey's ideas, as many different factors and people were involved in the programme. However, it is equally clear that according to Dewey's explicit assumption, the value of a theoretical concept should be measured by its ability to respond to human needs, that is to instances arising from our daily interactions with both the natural and social environment to which we belong. In other words, Dewey believed that the strength and resilience of an idea must be measured through the contribution it can make to changing problematic conditions by revising or improving them.

8 For this reason, in the present paper ${ }^{6}$ I aim to closely investigate certain aspects and historical consequences of US cultural policy between the nineteen-thirties and the immediate aftermath of the war in the light of some theoretical assumptions they imply, and which appear to be variously connected to Dewey's reflections. As has just been 
noted, the largely transdisciplinary pragmatist assumption behind my argument is that it is necessary to acknowledge the reciprocal influence whereby a given theoretical conception is fruitful to the extent that it is capable of providing original answers to the problems arising in a specific historical context, while at the same time opening up new paths to be followed. The thesis which lies at the basis of Dewey's critique of compartmentalisation and the neat separation between facts and values is that the effectiveness of the tools used for analytical reflection must be measured against their capacity to modify the conditions of immediate qualitative experience - by either enriching or impoverishing it.

Obviously the influence of the American pragmatist first on the policies of the Federal Art Project and subsequently on Abstract Expressionists features both progressive aspects and more controversial points. Therefore I believe that an examination of some lights and shadows of these historical phenomena can in turn help us to rethink Dewey's theoretical approach to the arts and aesthetic experience as important opportunities for establishing democratic life.

Firstly I shall argue that Dewey's conception of art and aesthetic experience appears to have made a decisive contribution in expanding opportunities to enjoy the arts and in promoting widespread practices with the potential to be aesthetically satisfying. Dewey's ideas actually led to an undermining of the unquestioned hierarchy between the fine arts and crafts, between popular culture and design, etc. More problematic are their connections with a cultural policy aimed at building an American cultural identity in opposition to the dominant European one. Further questions regard the emergence of a wider art market.

11 Secondly, I will consider Dewey's influence on the Abstract Expressionists - an influence which is almost immediately evident in the way it shifted the artistic focus from art objects toward the experiential dimensions of artistic practices. Some problems regard the onset of a new fracture in terms of the accessibility of this kind of work for a general audience. Further difficulties are connected with a certain reinforcement of the conception of the artist as creative genius and with the related interpretation of artistic creation as extreme subjective expression.

\section{Openings of a Cultural Policy}

First of all I would like to stress that the proponents of the cultural policy of the Federal Art Project saw the so-called Great Depression as a social and cultural opportunity, in open conflict with conservatives, who believed that every resource being spent in those sectors was wasted in a period of severe austerity. This point must be underlined, notwithstanding all the limits of any operation in support of a national cultural policy such as the one advanced by the Roosevelt administration in the nineteen-thirties.

13 In particular, the Deweyan Holger Cahill sought to turn the profound crisis into an opportunity for democratizing access to culture and the arts, by working through two complementary channels.

On the one hand, he carried out a series of measures to facilitate access to the highest and most traditional artistic culture by disseminating temporary exhibitions as far as the most remote provinces of the United States and by paving the way for the popularization of art and for artistic debate in popular magazines, not least through a widespread use of 
radio broadcasts. On the other hand, Cahill sought to deconstruct traditional established boundaries between the fine arts and crafts by promoting the establishment of an Index of American Design, which aimed to collect and reproduce the finest historical and contemporary American craft products.

The breaking down of the boundaries between high and popular culture mainly occurred through a far-reaching reform carried out by several American museums, under the direct influence of John Cotton Dana. The latter sought to apply to museums - especially the Newark Museum in New Jersey - the same change that he had brought to the libraries he had previously directed. Museums and libraries were viewed not simply as places for storing and revering products of high culture, but as active workshops for developing skills and for engaging with the techniques, contents and theoretical assumptions of past works, with their actual fruition and new artistic possibilities in view. Many areas were opened to the public, and new opening times and reduced admission charges were offered. Above all, a significant change in this direction with regard to museum investments took place: instead of continuing to acquire works from the past, especially European ones, which had particularly exorbitant prices, it was decided to focus on the purchase of craft products and especially products from the emerging field of industrial design, thus for the first time calling into question the distinction between works of art and industrial products - something destined to become a central feature of much twentieth-century art.

16 On the other hand, from a Deweyan perspective the financial support of many unemployed artists was effective in at least two ways. On the one hand, artists were hired to produce murals or posters, that is, not primarily objects to be relegated to museums, but artifacts to be displayed in public places, and capable of reworking their common cultural roots in an innovative manner. On the other hand, artists were treated as workers rather than as extraordinary geniuses, that is as individuals able to contribute with their own specific personal practice to a wider, shared practice. ${ }^{7}$

17 It is evident that these phenomena as a whole entail and are based on a conception of artistic creation and enjoyment, as well as of the relations between individual initiative and social context, that differs significantly from that of the late-Romantic tradition. ${ }^{8}$ As Dewey clearly states in Art as Experience, the expressive act cannot be identified with an anthropological version of creatio ex nihilo; clearly, the creating subject plays a crucial role, but as an individual medium rather than as a genius sparking a process. Expression, as Dewey said, consists in a peculiar transformative process through "the alembic of personal experience" of materials which originate from a common world. Besides, an object becomes "expressive" not when it externally conveys a subjective mental state or emotion, but when it constitutes an opportunity for innovative experiences of the shared world for those who appreciate it.

It should be pointed out in this regard that many of the future Abstract Expressionists were subsidized by the Federal Art Project. Some of them maintained such a shared, participatory approach to artistic production, as in the case of Joseph Albers. Others cultivated the myth of a subjective expression of their emotions that was carried to extremes, in conflict with Dewey's position - a conflict which has not been picked up by scholars, but which I shall return to in the fifth section of this paper.

Finally, one of the most successful initiatives of the Federal Art Project, sponsored by Cahill himself, must be mentioned: the establishment of Community Art Centers. These were not meant as spaces for merely enjoying existing works of art, but as active 
resources for promoting artistic production from the bottom up. Seen from the point of view of Dewey's democratic aesthetics, one of their most important aspects can be identified as the opportunity they provided to acquire various techniques, as well as new appreciation and production habits and skills, which could prove satisfying for individuals and re-accustom them to the aesthetic enjoyment of their own work. Indeed, as early as in 1922, in Human Nature and Conduct, Dewey had stated that equating work with exertion should not be taken as a natural given, but rather as the consequence of a by now hardened, regressive habit caused by industrial capitalism, and in particular of the one-sided pursuit of profit. ${ }^{10}$ Besides, Community Art Centers were intended to serve as places for social gatherings and shared enterprises. Individual activity here stemmed from a plural context through sharing or diversification, or - far more often - through conflict, and it was on this public testing ground that it had to measure its own effectiveness.

\section{Building an American Cultural Identity}


compartmentalization of life tending to expunge aesthetic pleasure from work by confining it to the sphere of leisure time. ${ }^{13}$ Dewey also insists on the nationalistic and imperialistic claims that have historically characterized the creation of the first great European museums, starting from the Louvre. He was deeply conscious of the role played by cultural and artistic heritage in the symbolic and political affirmation of national identity, and regarded it as one of the factors that had historically led to the establishment of the "museum conception of art," to the fetishization of artworks and their distancing from life experiences. ${ }^{14}$

In his analysis, the American philosopher strongly stresses the connection of art to its social context and, ultimately, of artistic experiences to the community in which they are rooted, in which they live and die. The roots of individual acts of expression in previous experiences belonging to a shared world is underlined too. Nevertheless, from a Deweyan point of view it is not a question of hoping merely to restore shared past conditions and habits of appreciation on the part of communities - that is, of artificially creating a past and tradition that no longer exist; rather, it is a matter of asking whether a certain aesthetic experience or work of art from the past is still capable of meeting the demands of today's shared life, and, if so, which ones. Nor should the artist limit himself to celebrating the common matter from which he draws his own energies, confirming traditional social expectations and habits. If his role is to mediate and not initiate the process of artistic expression, this does not mean that he has merely to translate what was previously there, because creation implies transformation, a reworking of earlier materials and energies into something new, which is truly able to offer experiences of the world that are different from previous ones, in contrast to a settled tradition, ensnared within its own habits. Artistic production is part of the social space whence it comes and in which it is rooted. It does not merely reflect this space, but somehow also operates within it, contributing to defining it from within, in a process which nevertheless remains structurally open. The same applies to fruition: it is not a matter of restoring a world buried and preserved through artworks, but rather of inquiring whether and in what ways these works are still a vital part of our contemporary world, whether they are capable of operating within this world so as to modify it - first of all by questioning our own expectations and our most ingrained habits, and by broadening and enriching our own interactions with the natural world and others.

We are thus forced to conclude that these theoretical arguments - which would indeed have been difficult to apply in practical terms - were set aside in favour of a political strategy centered on identity-building, and reflecting the tragic historical and political circumstances of its conception. In this regard, it is worth recalling that on the eve of the Second World War conservatives went so far as to accuse the Federal Art Project of supporting communism and not adequately sustaining the USA and American cultural identity.

\section{The Positive and Negative Aspects of Creating a Market for Cultural Heritage}

Another controversial aspect of the Federal Art Project we have to consider now regards the creation of an art market which was mainly directed to the middle classes as a way of meeting the chiefly symbolic needs of this sector of the population, while overlooking the "aesthetic needs" of all other citizens. Dewey showed he was fully aware of the problem 
when he argued that "the conditions that create the gulf which exists generally between producer and consumer in modern society operate to create also a chasm between ordinary and esthetic experience." ${ }^{15}$

Historically among those who supported the Federal Art Project there were those who were resolutely opposed to market economy, and who saw the opening up of culture to the economy as the beginning of an inevitable process of commodification of art and culture as well. But there were also more progressive tendencies, which saw the opening up of arts and culture to markets and industrialization as an opportunity to set in motion processes of democratization of consumption, accompanied by the deconsecration of items the possession of which was restricted to a very limited elite. ${ }^{16}$ Cahill belonged the latter group and his line prevailed.

On the one hand, the opening up of museums to crafts and industrial design, together with the creation of the Index of American Design, expanded the range of artworks that could be purchased from works of "high" art alone to cultural goods in the broader sense - which, as Bourdieu has shown, range from classical music to furnishings, clothing and culinary choices. ${ }^{17}$ This clearly represents a decisive break from the previous situation.

On the other hand, the ever wider use of advertising, both in printed form (through posters and billboards, as well as magazines) and by radio, together with the increasingly systematic use of marketing techniques, effectively produced a striking expansion of the market for artistic goods, which became accessible to the American middle class. At the same time the emergence of a strong domestic demand for this kind of goods contributed to making artistic production gradually independent of government support.

However it is clear that even if Dewey was deeply conscious of the social implications of the construction of an art market, his criticism of what in Europe was called the "differentiation of the aesthetic" did not consist in naively invoking a late romantic return of art to life by ingenuously ignoring its economic structures. Recognizing that aesthetic and artistic practices are not foreign to and autonomous from other forms of human interaction with the environment also entailed admitting that artistic production is never independent from economic structures - be it the case of Renaissance customers commissioning a work from a craft workshop, or in that of a nineteenth-century German prince supporting a poet through a life annuity.

32 The fact of having an increasing numbers of people willing to pay for cultural goods that had become accessible to the average American was no bad thing in itself: indeed, it partly contributed to the deconsecration of a sphere of cultural heritage and activities the exclusiveness of which had until then confirmed existing social divisions. Yet, it is clear that from a Deweyan point of view we should still ask ourselves whether promoting the consumption of cultural goods through wide-scale purchases represents the only or main way of favoring a more democratic and satisfactory enjoyment of a shared world.

Obviously it would be reductive as well as unfair not to recognize that establishing a wider art market is a very different thing from building cultural democracy. Dewey basically understood democracy as a form of shared life in which individuals are able both to make critically aware choices and to enjoy and intensify the qualitative aspects of their experience. The kind of "consummatory experience" he was referring to is not a form of consumerism, based on purchasing, exhausting and discarding products. Instead it is a sort of experience in which the satisfaction of the human need for qualitatively rich and intense relationships is expansive and energetic. ${ }^{18}$ 

alternative relations between aesthetics, politics and economy - indeed, there would be much need for this in the present historical circumstances. Dewey's ideas are promising but we require a more carefully articulated and detailed discourse on the relations between the arts and other life practices - in particular, alternative proposals concerning modes of production and fruition that take into account both economic and social factors.

\section{From the Federal Art Project to Abstract Expressionism}

The argument that Dewey's thinking profoundly influenced so-called Abstract Expressionism was brought forward by Stewart Buettner as early as 1975. Several years later - in 1998 - Maurice Berube provided further historical evidence in support of the theory. ${ }^{19}$

Many of the most successful American abstract artists during the following years were economically sustained by the Federal Art Project, including many extremely different personalities such as Arshile Gorky, Willem de Kooning, Jackson Pollock, Marck Rothko, Barnett Newman, Adolph Gottlieb and Clyfford Still.

However, now that a reconstruction of the Federal Art Project from a history of culture perspective is available, the picture appears much clearer and confirms the links between Dewey's approach and American Abstractionism in the forties and fifties, something which had already clearly been noted by Buettner. This kind of comparison nonetheless also reveals a number of discontinuities, especially regarding the social implications of an artistic movement which was itself extremely varied. into crisis. They were attacked above all by conservatives and in some cases were even terminated. They were accused by conservatives of promoting forms of socialism, or even of supporting communism, while not sufficiently supporting American cultural identity as opposed to European culture. Yet some critics also came from less nationalistic fringes: they argued that systematic (rather than merely short-term) national support for the arts might, in the long term, lead to the control of cultural production by the state - and it was precisely on this front that a bill aiming to transform Federal Art Project interventions into a stable Federal Bureau was voted down. However, criticism was also leveled by artists with reference to the quality of the models, contents and results provided by painters subsidized by the state. The Association of Fine Arts, which grouped together 5.000 registered artists, railed against the lowering of "truly artistic" standards to those of the common man. In 1939 Clement Greenberg wrote that popular culture, and even more so "average" culture, would destroy the avant-garde and all merit, because they brought about a dangerous confusion in evaluation standards. ${ }^{20}$

addition, industrial production, directly or indirectly related to war needs, was rapidly increasing, reducing the need for government support that had been so strong during the previous economic and social crisis.

41 In the more specifically artistic sphere, the realism that characterized artistic production in the nineteen-thirties was interpreted as provincialism, and abstract art was now 
perceived as the main path to be followed in the pursuit of an originally American and truly innovative art.

\section{Pollock through the latter's acknowledged master, Thomas Benton, and on Robert} Motherwell. Motherwell is commonly considered the most intellectual figure in that constellation of artists: he had read Art as Experience and studied under Meyer Schapiro, Dewey's colleague at Columbia, from whom the pragmatist philosopher had requested an opinion on the final chapters of the book before its publication.

Maurice Berube has further backed Buettner's theory with interviews and accounts that confirm how widely held Dewey's pragmatist aesthetics was among the Abstract Expressionists. Particularly significant is an interview by Robert Mattison Staltonsall with Robert Motherwell, who expressly acknowledged his debt to Dewey, so much so that he even referred to the sort of experimentalism he was practizing in painting as "radical empiricism." ${ }^{23}$ Another important document consists in a collection of interviews with six exponents of Abstract Expressionism - Motherwell, De Kooning, Rothko, Hoffman, Gorky and Mark Tobey - conducted by William Seitz for his dissertation, published in 1955. Additional evidence for the spread of Dewey's thought, whose texts were not only read 
but also presented and discussed in various artistic circles at the time, is provided by the fact that Seitz himself, as recalled by Berube, was one of these artists. A practicing painter and young employee of the Federal Art Project, Seitz frequented abstract artists' gathering places such as The Cedar St. Tavern and The Club. In general, I believe that Buettner's analysis of Dewey's influence is correct, but needs to be integrated by also taking account of the social implications of Abstract Expressionism I have mentioned above.

No doubt the most striking parallel between Dewey's theories and the works of Abstract Expressionists is to be found in his decisive shift of attention from the aesthetic product to the experience of which it is the result. As in the case of the Abstract Expressionists, disputing the primary role of objects does not mean that material aspects are considered marginal. On the contrary: materials, colors and techniques are of great significance, but instead of being regarded as ingredients designed to create a work of art as a particular kind of thing, they are understood as materials and energies in action, together with perceptual and motor habits, bodily and mental techniques of selection, revision and interpretation, and active and passive dispositions that contribute towards creating an innovative experience. Certainly the action of dripping paint onto canvas produces a certain kind of thing - possessing, among other features, a very high economic value but a work of art consists primarily in a certain type of practice: a qualitative interaction with an environment within a complex space, where the artist feels himself to be an integral part of this space, rather than an external consciousness controlling the product before him. For this reason the name "Action Painters" which Arnold Ronsenberg gave to some of these painters helps appreciate their affinity with Dewey's approach.

From Dewey's criticism of the idea of considering art as being primarily a certain kind of entity comes his argument against confining art to museums, turning it into "ethereal things" and removing it from active social life. On the one hand, most of these artists, who had been members of the Federal Art Project for various reasons, no longer regarded the isolation of art in museums as acceptable. On the other, both practical and theoretical reasons contributed to challenging the "museum conception" of art. A tendency to paint large canvases came partly from the very strong stress placed by the former federal programme on murals, on paintings often incorporated directly within collective urban contexts. But it also probably came from Dewey's idea that the artist's relation with his/ her work is not frontal, that it no longer implies a complete control of the canvas, as is usually implied by representational paintings. The artist in turn is conceived as part of an environmental game he engages in from within. He does not dominate the environment, but structurally relates to it, first of all through his whole body. To this point we must surely add the fact - noted by Buettner - that the work of these painters was initially rejected by traditional museums, who obviously felt that these experiments diverged from their established canons. The rejection of the "museum conception" was not only active and therefore intentional, but was also borne.

51 A more complex crux concerns the role attributed to emotions in artistic expressions. It must be said that seeking points of contact in a conception of painting as an outward expression of the artist's subjective emotions is misleading.

52 A conception of artistic creation of this type is certainly present in many artists from this group. Jackson Pollock's words are especially revealing in this respect: "A method of painting is a natural growth out of a need [...] I want to express my feelings rather than 
then illustrate them [because] the modern artist expresses his feelings rather than imitating [nature]." ${ }^{24}$

However, this kind of interpretation is very far from Dewey's perspective, who, as recognized by Buettner, assigns a central role to emotions in artistic creation, but does not understand them in terms of expressed subjects - whereby a dark color would express the artist's anger, for instance, and black, rapid, angular strokes his aggressiveness. The artist's emotions should rather be understood as a form of sensitivity which is not primarily cognitive, which makes it possible to guide a new elaboration of available materials: a certain emotion serves as an implicit criterion for their selection and new composition, and controls the rhythmic progression according to which a certain interaction takes place, implicitly testing its effectiveness. ${ }^{25}$ It seems that Robert Motherwell in particular had in mind the idea of claiming an emotional rather than an intellectual base for artistic expression.

But in this case too there is a clear tendency on the part of both the Expressionists and their interpreters to equate the emotional with the irrational. Dewey is profoundly distant from this kind of assimilation, as his criticism of the alleged primacy of cognitive experience to the detriment of the qualitative and aesthetic aspects of immediate experience acknowledges that the latter has an irreducible significance and constitutes a form of awareness. But it is likely that with respect to this aspect it was European Surrealism, rather than Dewey, which exerted a decisive influence on the Action Painters - and it is worth pointing out that Croce himself misunderstood Dewey on this point. ${ }^{26}$

However, although aspects of this kind might seem very far from the question of the historical effectiveness of Dewey's aesthetics, they actually evidence a new swing in the perception of the artist's role in society.

The Federal Art Project led to a democratic demythification of the role of the artist, who was seen as a worker who responds to shared social needs and helps to define experiences which are not merely individual. In contrast, Abstract Expressionism led to a new glorification of the "artist-as-martyr" figure, to a renewed version of the late Romantic genius, spiced up by a touch of social marginalization. And even a superficial consideration of this phenomenon reveals that all of this led to deep changes in the art market. Works by American artists achieved sky-high prices over the years, not only in comparison to works from the federal programme years, but also compared to European abstract artists who did not have a significant market in the United States. ${ }^{27}$

\section{A Balance?}

As previously affirmed, it would be tritely incorrect to consider the policy of the Federal Art Project, or the culture pursued by American abstract avant-garde artists as mere translations of Dewey's thought.

However, as is well known, his pragmatism forces philosophy to deal with "problems of men," or at most with more or less institutionalized forms of relation between those who produce art and the communities who support them and benefit from artistic production. On the contrary, it is not a question of merely examining the role played by the arts in social practices, but also of understanding the extent to which a theoretical investigation can identify solutions and establish what can or must be done. 
59 As I have sought to argue in this article, the attempts to translate certain Deweyan principles into a cultural policy were partly positive and partly more ambivalent. The point is that these attempts were grafted onto pre-existing social relations and their own largely unconscious, habitual demands. In other words, a common space, shared peacefully or more frequently in a conflictual manner, existed prior to these kinds of cultural policies, which were pursued at various levels - giving these levels different directions and actively contributing to their transformation.

60 As already noted in the introduction, I believe we must seriously consider Dewey's suggestion to formulate a philosophy of art which, far from being "sterilized," can make "us aware of the function of art in relation to other modes of experience," and especially show "why this function is so inadequately realized" by identifying "the conditions under which the office would be successfully performed." ${ }^{28}$ But we must also acknowledge that philosophy alone is unable to take into account certain issues or articulate certain details which are evidently not only implementary, but are the actual means that contribute to establishing the goals to be achieved. ${ }^{29}$

61 From this point of view, the role of philosophy can no longer be that of providing a preliminary delineation of the field of play of the empirical sciences. Instead, philosophy must be seen to operate within a process of collaboration which, while capable of offering some guidelines, is not self-sufficient, but rather requires one to establish with others what can or must be pursued, starting from an assessment of how this goal might be achieved.

\section{BIBLIOGRAPHY}

ALEXANDER T.M., (1987), John Dewey's Theory of Art, Experience and Nature. The Horizons of Feeling, Albany, State University of New York Press.

BENJAMIN W., (1955), Das Kunstwerk im Zeitalter seiner technischen Reproduzierbarkeit, Frankurt a. M., Suhrkamp.

BERUBE M., (1998), “John Dewey and the Abstract Expressionists," Educational Theory, 48/2, 211-227.

BLUMENBERG H., (1957), “Nachahmung der Natur. Zur Vorgeschichte des schöpferischen Menschen," Studium Generale, 10, 266-283.

BOURDIEU P., (1979), La distinction. Critique sociale du jugement, Paris, Minuit.

BUETTNER S., (1975), "John Dewey and the Visual Arts in America," The Journal of Aesthetics and Art Criticism, 33/4, 383-391.

CIMINELLI M.L., (2008), "Salvaguardia del patrimonio culturale immateriale e possibili effetti collaterali: etnomimesi ed etnogenesi," in L. Zagato (ed.), Le identità culturali nei recenti strumenti Unesco, Padua, Cedam, Padua, 2008.

DEWEY J., (1916), Democracy and Education, New York, Macmillan. 
DEWEY J., (1983), Human Nature and Conduct, in Volume 14: 1922 of The Middle Works, 1899-1924, (MW), Carbondale and Edwardsville, Southern Illinois University Press.

DEWEY J., (1988), Three Independent Factors in Morals, in Volume 5: 1929-1930 of The Later Works, (LW), Carbondale and Edwardsville, Southern Illinois University Press, 279-288.

DEWEY J., (1985), Ethics, in LW 7.

DEWEY J., (1989), Art as Experience, in LW 10.

DEWEY J., (1991), Logic: The Theory of Inquiry, in LW 12.

DREON R., (2007), Il sentire e la parola. Linguaggio e sensibilità tra filosofie ed estetiche del novecento, Milano-Udine, Mimesis.

DREON R., (2012), Fuori dalla torre d'avorio. L'estetica inclusiva di John Dewey oggi, Genova, Marietti 1921.

FESMIRE S., (2003), John Dewey and Moral Imagination. Pragmatism in Ethics, Bloomington, Indiana University Press.

GRIEVE V., (2009), The Federal Art Project and the Creation of Middlebrow Culture, Urbana and Chigaco, University of Illinois Press.

JAY M., (2002), “Somaesthetics and Democracy: Dewey and Contemporary Body Art," Journal of Aesthetic Education, 36/4, 55-69.

KRISTELLER P. O., (1983), “'Creativity' and 'Tradition',” Journal of the History of Ideas, 44/1, 105-13.

MATteRn M., (1999), “John Dewey, Art and Public Life,” The Journal of Politics, 61/1, 54-75.

MELVIN G., (1992), “The Social Philosophy Underlying Dewey's Theory of Art,” in J. E. Tiles (ed.), John Dewey: Critical Assessments, Volume III: Value, Conduct and Art, London and New York, Routledge.

SENALDI M., (2007), “Art as Experience e l'arte contemporanea,” in L. Russo (ed.), Esperienza estetica. A partire da John Dewey, Palermo, Aestetica Preprint, 2007.

WESTBOOK R., (1991), John Dewey and American Democracy, Ithaca and London, Cornell University Press.

\section{NOTES}

1. This thesis was already put forward by Melvin 1992, in an old article. Robert Westbrook particularly emphasized the intertwining of aesthetic, social and political issues in his work John Dewey and American Democracy (Westbrook 1992). More recently the same claim was made by Mark Mattern (Mattern 1999); it has also been originally developed by S. Fesmire in his book John Dewey and Moral Imagination. Pragmatism in Ethics (Fesmire 2003), which focuses mainly on the aesthetic implications of ethics.

2. LW 10: 16.

3. What is of central importance here is the distinction between rigid, obtuse behaviours and intelligent, flexible habits capable of fostering opportunities for experiences other than those already consolidated, which is outlined by Dewey in his Human Nature and Conduct, MW 14. The basic assumption of this study in "social psychology" is particularly interesting: that man is not only a naturally social individual, but also an organism whose behavior is structurally mediated by habits. 
4. On this point see the previously cited volume by Westbrook, who points out that Dewey's critics accused him of not providing a substantive definition of values, with a positive, hierarchical order for them (in particular see "Constructing Good," Westbrook 1992: 402). But the point is that for Dewey such determination is not possible, not only out of respect for each individual's "capabilities," but above all because he believed that moral situa- tions are structurally indeterminate: it was clear in his mind that in most of the existential situations in which we have to take a decision we have different criteria at our disposal that are equally good and shareable but in conflict with one another and which render our decision uncertain and without any unambiguous outcome, if not retrospectively (see Dewey, Three Independent Factors in Morals, in LW 5: 279-88).

5. See Grieve 2009. The text is a wide-ranging and detailed source of Federal Art Project cultural history and much of the information I have used in these paragraphs has been drawn from it.

6. I have instead examined the more strictly theoretical aspects of Dewey's aesthetics in Dreon 2012, as well as before that in two chapters devoted to Dewey in Dreon 2007.

7. I think it is in this that we can interpret Mark Mattern's thesis, which assigns an important role to the arts in the public life of a democracy, because art "is a form of communication." Indeed, Dewey often argued that the term "communication" should be literally understood as "doing something in common" (Mattern 1999: 54). The connection between "communication" and "common" can be found both in Art as Experience (LW 10: 248), and in the following volume Logic: The Theory of Inquiry (LW 12: 52), as well as in the earlier text citied by Mattern, Democracy and Education (Dewey 1916: 4).

8. On this point see Blumenberg 1957 and Kristeller 1983.

9. LW 10: 88.

10. MW 14, see chapter 9, "Changing Human Nature."

11. See Grieve 2009, chapter 2, "Inventing a Usable Past."

12. On this point see Ciminelli 2008.

13. On these aspects see in particular Dewey, MW 14.

14. These are now extremely relevant issues in Europe, as well as elsewhere. On these matters, see Zagato (ed.), 2008.

15. I shall quote here the impressive paragraph leading up to this statement in Art as Experience, which reminds one of Bourdieu's La distinction: "The nouveaux riches, who are an important byproduct of the capitalist system, have felt especially bound to surround themselves with works of fine art, which, being rare, are also costly. Generally speaking, the typical collector is the typical capitalist. For evidence of good standing in the realm of higher culture, he amasses paintings, statuary, and artistic bijoux, as his stocks and bonds certify to his standing in the economic world. Not merely individuals, but communities and nations, put their cultural good taste in evidence by building opera houses, galleries, and museums. These shows that a community is not wholly absorbed in material wealth, because it is willing to spend its gains in patronage of art. It erects these buildings and collects their contents as it now builds a cathedral. These things reflect and establish superior cultural status, while their segregation from the common life reflects the fact that their are not part of a native and spontaneous culture" (LW 10: 14-15).

16. 16 On this aspect see Walter Benjamin's famous essay Das Kunstwerk im Zeitalter seiner technischen Reproduzierbarkeit (Benjamin 1955), where loss of aura is perceived as an ambivalent phenomenon: at most it might carry the opportunity for a future democratisation of art appreciation.

17. See Bourdieu 1979.

18. References of this kind are numerous not only in Art as Experience, but also in Dewey's ethical reflections, where it is very clear that a democracy geared towards the establishment of the 
common good (although it would be better to speak of "common goods" in the plural) must promote individual happiness. See LW 7: 198.

19. The seminal article on Dewey's influence on Abstract Expressionists is that by Stewart Buettner, John Dewey and the Visual Arts in America, (Buettner 1975). Several years later a text by Maurice R. Berube, John Dewey and the Abstract Expressionists (Berube 1998) was published. In Italy an essay appeared by Marco Senaldi, based on previous ones (Senaldi 2007).

20. See Grieve 2009: 175.

21. An interpretation of this kind is favoured by Jay 2002.

22. See Buettner (1975: 389).

23. See Berube (1998: 219-20).

24. Cited by Berube, 1998: 217.

25. For an in-depth discussion of the concept of emotion and its role within aesthetic expression, I would refer to the second and third chapters of my aforementioned book, Fuori dalla torre d'avorio (Dreon 2012).

26. For a detailed analysis of the exchange between Dewey and Croce,one see Alexander 1987, chapter 1 "The Pepper-Croce Thesis."

27. Consider for example the difference in price between Dubuffet's and Fautrier's works. The two painters are often considered "brother-artists" by critics, but while the former was active in the US art market, the latter worked in the European one.

28. LW 10: 17.

29. The implied reference is to Dewey's criticism, continually problematising our habitual opposition between means and ends, which, however, I cannot deal with in this paper.

\section{ABSTRACTS}

The purpose of this paper is to consider Dewey's influence on American artistic culture between the nineteen-twenties and the nineteen-fifties by focusing on the social and political implications of his approach to art in terms of experience. This entails recapturing, in a concise form, the impact of Dewey's thought on the development of the Federal Art Project and on Abstract Expressionism. On the basis of the pragmatist assumption that the soundness of a theoretical proposal is to be measured according to its capacity to meet the difficulties arising in our everyday interactions, the present paper systematically examines the theoretical implications of Dewey's aesthetics in the light of the historical consequences of a specific cultural policy. Dewey's conception of art and aesthetic experience appears to have made a decisive contribution by providing new opportunities to enjoy the arts and by widely promoting practices with the potential to be aesthetically satisfying. Dewey's ideas actually led to an undermining of the hierarchy between the fine arts and crafts, between popular culture and design, etc. More problematic are their connections with questions of cultural identity and of art market. Dewey's influence on the Abstract Expressionists is evident in the way it shifted the artistic focus from art objects toward the experiential dimensions of artistic practices. Some problems regard the accessibility of this kind of works for a general audience and a certain reinforcement of the conception of the artist as creative genius, included the related interpretation of artistic creation as extreme subjective expression. 


\section{AUTHOR}

\section{ROBERTA DREON}

University Ca' Foscari, Venice, Department of Philosophy and Cultural Heritage

robdre[at]unive.it 